\title{
Proceeding
}

Supplementary Issue: Summer Conferences of Sports Science. $8^{\text {th }}$ International Workshop and Conference of the International Society of Performance Analysis of Sport (ISPAS), 11-1 th of September 2019 (Budapest, Hungary) "Technology meets Practice and Science".

\section{Everesting challenge attempt strategy: A case study}

\author{
LEONARDO CESANELLI $\triangle$, GIORGIA VICI, DALIA CAMILLETTI, ROBERTO CECI, LUCA BELLI, \\ VALERIA POLZONETTI
}

School of Biosciences and Veterinary Medicine, University of Camerino, Camerino, Italy

\begin{abstract}
The Everesting challenge (repeat any hill, anywhere in the world, until you climb an altitude of $8848 \mathrm{~m}$; the equivalent of $\mathrm{M}$. Everest) is becoming an increasingly popular challenge. The physical and metabolic stress to which the body is exposed during this type of exercise is unusual and it is also particularly challenging for coaches, trainers and sport nutritionists. The aim of this study is to analyse the parameters and key details necessary to optimize a 10-week training protocol for an ultra-endurance performance like the Everesting challenge. An ex-élite cyclist, trained individual (male; 26 years; $181 \mathrm{~cm} ; 71,7 \mathrm{~kg} ; 21,9 \mathrm{BMl}$ ) followed a 10 weeks training and nutrition program to reach his peak performance and attempt the challenge. Body composition analysis checks (body weight, body circumferences, skinfold thickness and bioimpedance analysis) and performance tests (Conconi, Functional Threshold Power, Maximum Lactate Steady State) were planned at week 1, 5 and 10. After 10 weeks FTP increased from 245 to $267 \mathrm{~W}$ and at MLSS from 252 $\mathrm{W}$ to $270 \mathrm{~W}$. Body weight decreased from $71,7 \mathrm{~kg}$ to $68,3 \mathrm{~kg}$ and body fat from $10,7 \%$ to $6,8 \%$ (JacksonPollock 7 sites). The individual was able to accomplish the Everesting challenge concluding his ride in $13 \mathrm{~h} 34 \mathrm{~m} 27 \mathrm{~s}$, average power $162 \mathrm{~W}$, average heart rate $139 \mathrm{bpm}, 7685 \mathrm{kcal}$ consumed. 10 weeks of strategically planned nutrition and training program may be sufficient to prepare an élite athlete or a welltrained individual to attempt an ultra-endurance challenge like the Everesting. Keywords: Cycling; Training; Ultra-endurance; Endurance.
\end{abstract}

Cite this article as:

Cesanelli, L., Vici, G., Camilletti, D., Ceci, R., Belli, L., \& Polzonetti, V. (2019). Everesting challenge attempt strategy: A case study. Journal of Human Sport and Exercise, 14(5proc), S2400-S2409. doi:https://doi.org/10.14198/ihse.2019.14.Proc5.55

Corresponding author. School of Biosciences and Veterinary Medicine, University of Camerino, Camerino, Italy.

E-mail: cesanelli.leonardo@gmail.com

Supplementary Issue: Summer Conferences of Sports Science. $8^{\text {th }}$ International Workshop and Conference of the International Society of Performance Analysis of Sport (ISPAS), 11-13 th of September 2019 (Budapest, Hungary).

JOURNAL OF HUMAN SPORT \& EXERCISE ISSN 1988-5202

(c) Faculty of Education. University of Alicante

doi:10.14198/jhse.2019.14.Proc5.55 


\section{INTRODUCTION}

The Everesting bike challenge (repeat any hill, anywhere in the world, until you climb an altitude of $8848 \mathrm{~m}$, the equivalent of $\mathrm{M}$. Everest) is becoming an increasingly popular ultra-endurance challenge. To date more than 3400 bike challenges have been successfully completed, with an attempt lasting from 10 to 24 hours. The optimisation of the athlete's performance before the attempt is particularly challenging for coaches, trainers and sport nutritionists.

In the last decade interest and participation in ultra-endurance events has increased significantly all over the world (Scheer, 2019; Knechtle and Nikolaidis, 2018).

An ultra-endurance activity is generally recognised as being exercise which lasts for more than 4 hours (Peters, 2003; Costa et al., 2019) or even more than 6 hours (Scheer, 2019). The physical and metabolic stress to which the athletes' bodies are exposed during activities like these is unusual and requires specially adapted nutritional and training support (Knechtle and Nikolaidis, 2018).

The athlete's nutritional status and level of energetic and nutritional support during training and competitions are associated with increases or decrements in exercise performance (Nikolaidis et al., 1995; Peters, 2003; Costa et al., 2018; Kerksick et al., 2018). Nutrition and its periodization are key factors in inducing and achieving functional metabolic adaptations and for improving substrate utilization during the activity (Costa, 2018; Jeukendrup, 2017). Proper nutrition is also fundamental to sustain the athlete energetically and structurally before, during and after training and competitions and to prevent and manage fatigue and gastrointestinal discomfort (Costa, 2018; Knechtle and Nikolaidis, 2018; Kerksick et al., 2018). Body composition analysis techniques coupled with performance analysis tests represent fundamental tools to evaluate the athlete's physical-metabolic condition as well as nutritional and muscular status and needs (Löllgen and Leyk, 2018; Lee et al., 2017; Bertuccioli et al., 2019, Heydenreich et al., 2017; Mazić et al., 2014; Beneke et al., 2011, Knechtle, B. 2014). Nikolaidis et al., 2019 reported how during preparation for an ultra-endurance competition the athlete's body composition is subject to marked changes, resulting mainly in a reduction in both body fat and fat free mass. Periodic body composition check-ups coupled with hydration status monitoring is fundamental to individuate the correct nutritional support and to periodize it in relation to the training and metabolic characteristics of the athlete.

Parallel with structured training programs, induced muscular and metabolic adaptations and finding the right pace to maximize performance, are also important physical-metabolic tests (Löllgen and Leyk, 2018).

However, an in-depth study, analysis or prediction of energetic-nutritional needs, fuel utilization and muscular-metabolic acute and chronic adaptions during an ultra-endurance event or preparation represents a complex challenge for researchers and/or sport science professionals (Rauch et al., 1998). Factors like the geographical location of the competition/trainings, the athlete's morphological and metabolic characteristics, the environment and unexpected race/training events, represent crucial variables impacting on exercise intensity and fuel utilization. Indeed, only a few studies reported direct data about ultra-endurance metabolic needs (Costa et al., 2018). Different studies analysed and reported the possibility of inducing specific metabolic adaptation through nutrition and training manipulation (Jeukendrup, 2017; Jeppesen and Kiens, 2012; Rauch et al., 1998; Costa et al., 2018 Burke et al., 2017; Volek et al., 2016). However, laboratory protocols in which exercise intensity, climate and other external factors (e.g. the emotive impact of a competition on the athlete) are standardized, may not always be representative of the athlete's real conditions during a competition/training and so unable to produce functional data to increase the athlete's performance. 
Fat utilization adaptation can be considered potentially beneficial for a medium intensity, steady state performance typical of many of ultra-endurance challenges, however data about the benefits and disadvantages of low carbohydrate high fat protocols are controversial (Costa et al., 2018; Jeppesen and Kiens, 2012; Burke et al., 2017; Volek et al., 2016). Considering that central fatigue, muscle damage, hydration status, muscle glycogen and blood glucose content and availability are the main limiting factors for endurance performance, managing them with nutrition, and nutrient periodization during the athletic season could represent one of the best strategies to induce metabolic adaptations, as well as improve the body composition and performance of the athlete (Jeukendrup, 2017; Impey et al., 2018).

Therefore, considering what has already been published on this topic, the main aim of this study is to analyse the impact of a relatively short (10 weeks) performance optimization program on metabolic and body composition adaptation and on an ultra-endurance event performance for an ex-élite endurance athlete.

\section{MATERIALS AND METHODS}

\section{Study Design}

To study the impact of 10 weeks of nutritional and training optimization on an ultra-endurance bike event a longitudinal case study was structured in which an ex-élite athlete was monitored periodically (T1, T2, T3) (Figure 1).

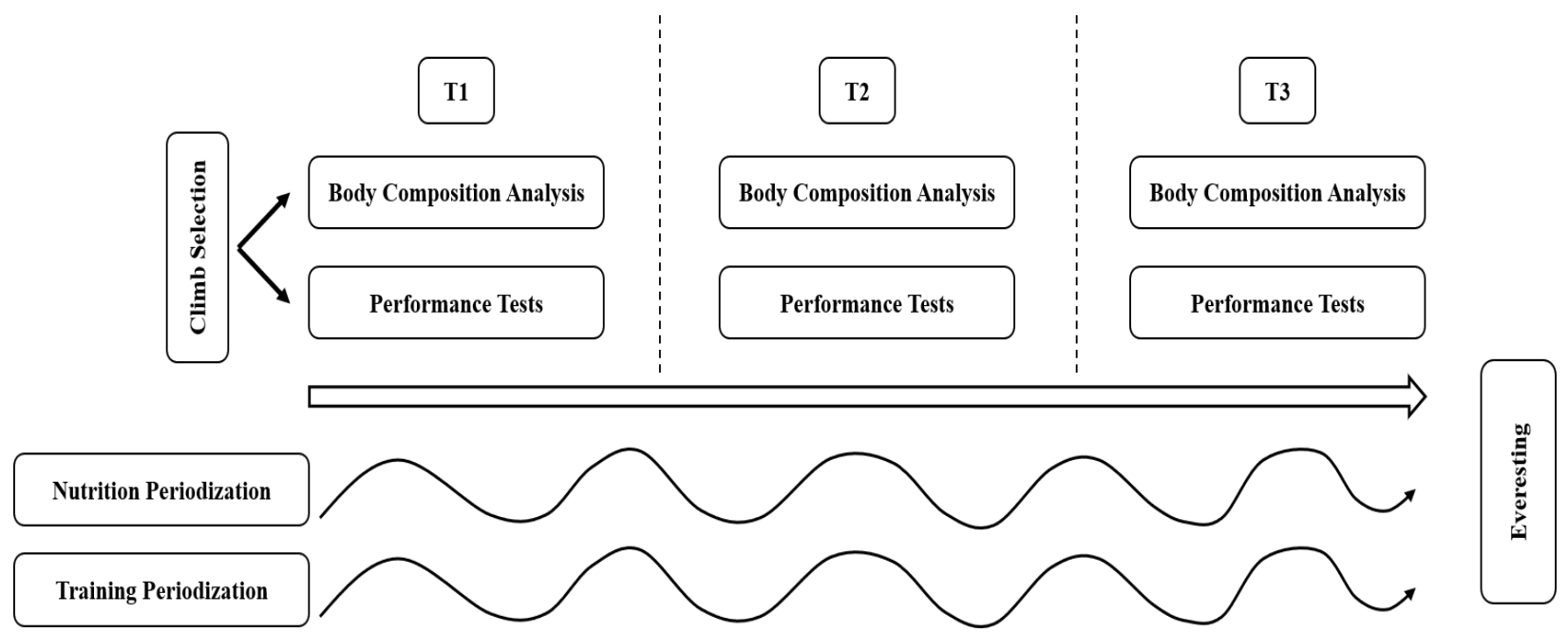

Figure 1. Study design.

\section{Participant}

We studied an ex-élite cyclist, well-trained individual (male; 26 years; $181 \mathrm{~cm} ; 71,7 \mathrm{~kg} ; 21,9 \mathrm{BMI}$ ) who has stopped competitive racing but continues to train occasionally. In March 2019 he asked our lab (NUTRICAM Food \& Health) if it was possible to prepare for the Everesting challenge in 10 weeks $(25 / 03 / 2019 \rightarrow 09-06$ 2019), maximizing his performance. The subject (M.B.) voluntary accepted to participate in the study and signed informed consent after being informed of the testing procedures according to the Declaration of Helsinki. 


\section{Nutrition periodization}

Resting metabolic rate (RMR) was analysed at T1 through indirect calorimetry (COSMED FitMate PRO COSMED Srl - Italy) following the methodology described by Compher et al., (2006). Daily caloric and macronutrients uptake was structured considering training volume and characteristics. In the first phase (T1 $\rightarrow$ T2) a caloric deficit was planned with low carb high fat as the prevalent dietetic approach. In the second phase (T2 $\rightarrow$ T3) calories progressively increased until the final week before the competition in which a caloric load was structured. In the second phase macronutrients uptake was strictly related to training goals.

\section{Body composition evaluation}

Body composition analysis checks were planned at T1, T2 and T3. Anthropometric data was collected following standardized international procedures. Body weight was measured using a mechanical balance scale (seca 813). Body circumferences were taken using a non-stretchable fiberglass insertion tape in different sites: abdomen, chest, left and right arms (both relaxed and contracted), left and right thigh (proximal, mid and distal) and left and right calf. Skinfold thickness was measured using a GIMA skinfold calliper, at different sites on the right site of the body: triceps, biceps, mid-axillary, chest, subscapular, abdominal, suprailiac, thigh, calf as described in NHANES manual (Centers for Disease Control and Prevention, 2007; Madden and Smith, 2016). Percentage of fat mass was estimate using 3 and 7-sites Jackson and Pollock equations (Jackson and Pollock, 1978). Tri-compartmental body composition was evaluated using Bioelectrical Impedance (BIA) using single-frequency bioimpedence (BIA AKERN 101, 50 $\mathrm{kHz}$, AKERN, Florence, Italy). An analysis of the value of resistance and reactance was carried out using BodyGram Plus@ software. Total Body Water (evaluating TBW); Extra and Intra Cellular Water (ECW; ICW); Phase Angle (PA) and Body Cell Mass (BCM) were considered (Piccoli et al., 1994).

\section{Training periodization}

After choosing the hill (Monte Conero - Ancona, Italy - 3,7 km, $374 \mathrm{~m}, 10 \%$ ) the first tests were planned to analyse climbing time and climbing effort. In the first phase $(\mathrm{T} 1 \rightarrow \mathrm{T} 2)$ the main training goals were to increase endurance capacity and in particular to sustain constant medium intensity workloads in progressively longer distance trainings (Zaryski et al., 2005; Hofmann and Tschakert, 2017). In the second phase (T2 $\rightarrow$ T3) the focus was on increasing lactate tolerance and anaerobic threshold, finding the right cadence (rpm) and rhythm/workload $(\mathrm{km} / \mathrm{h}-\mathrm{W})$ to cycle up Monte Conero 24 times. The week before the competition a progressive training deloading was planned.

\section{Testing protocols}

Performance tests were planned at T1, T2 and T3. Power output (W) was measured through a crankset power meter (@ Stages Cycling, LLC 2018), heart rate (bpm) and training data was acquired using a cyclocomputer (Bryton Rider 530 - Bryton Inc. 2017), blood lactate levels were measured using a blood lactate test meter (Lactate Pro ${ }^{\mathrm{TM}} 2$ LT-1730; Arkray Inc., Japan). A Conconi incremental test was performed on a cycle ergometer (Excite Bike Med - TECHNOGYM®) (Conconi et al., 1996). A Functional Threshold Power (FTP) 1-hour test was performed standardizing the route, weather conditions and time of day (Allen et al., 2019). Maximum Lactate Steady State Test was performed on consecutive days on the hill selected for the competition (Hoogeveen et al., 1997; Beneke, 2003; Billat et al., 2003). All the tests were performed after a "recovery" (active recovery training session) day.

\section{Challenge attempt strategy}

Based on data collected over the 10 weeks and from the tests performed, our goal was to conclude the challenge in less than $15 \mathrm{~h}$. We set the climbing power output to $65 \%$ of the FTP, hypothesizing a possible $5 \% / h$ decrement in performance from the FTP $1 \mathrm{~h}$ test performed and considering MLSS tests (Perez et al., 
2012). During the challenge the athlete remained constantly in contact with us and we were able to assess any pace increases or reductions. At the top of the climb and at the bottom of the descent two refreshment points were placed where the athlete was able to consume meals and scheduled supplies.

\section{Data Analysis}

Given the nature of the study, only a qualitative analysis was performed. All data analyses were carried out using GraphPad Prism version 7.0 (GraphPad Software, San Diego, CA, USA).

\section{RESULTS}

The athlete was able to accomplish the Everesting challenge concluding his ride in $13 \mathrm{~h} 34 \mathrm{~m} 27 \mathrm{~s}$, average power $162 \mathrm{~W}$, average heart rate $139 \mathrm{bpm}$ and $7685 \mathrm{kcal}$ consumed. Climbing data is represented in figure 2. The athlete lost $1,3 \mathrm{~kg}$ of body weight from the start to the finish of the attempt. Calories consumed were estimated to be about $5840 \mathrm{kcal}$ of which $45 \%$ carbohydrates, $14 \%$ proteins and $40 \%$ fats. The athlete consumed about 9 litres of water plus 4 litres of water with mineral salts and/or carbohydrates.

Climbing Time

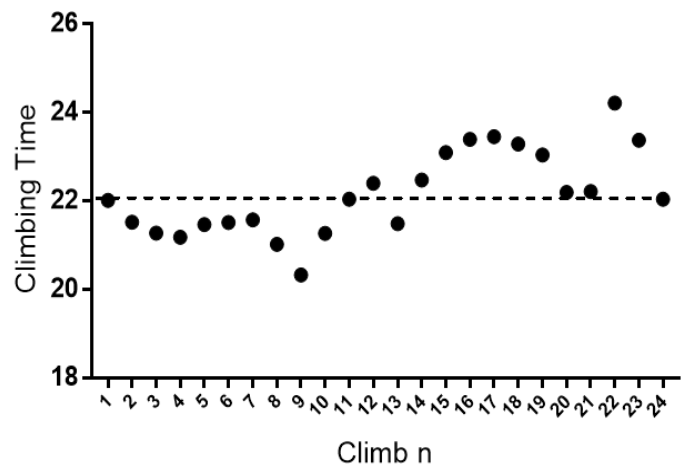

Mean Climbing VAM

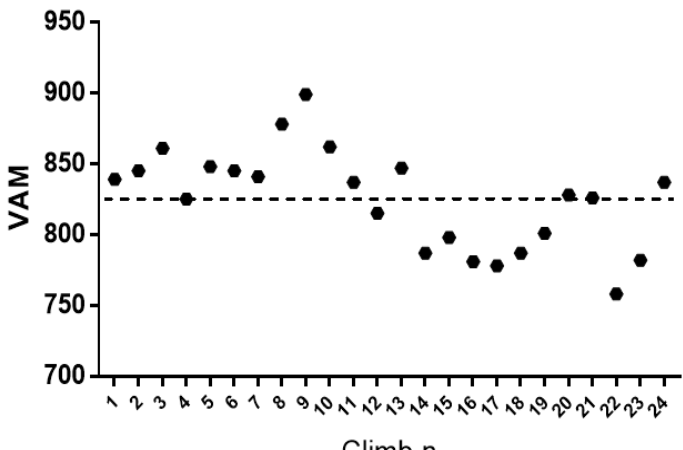

Climb $n$
Mean Climbing Watt

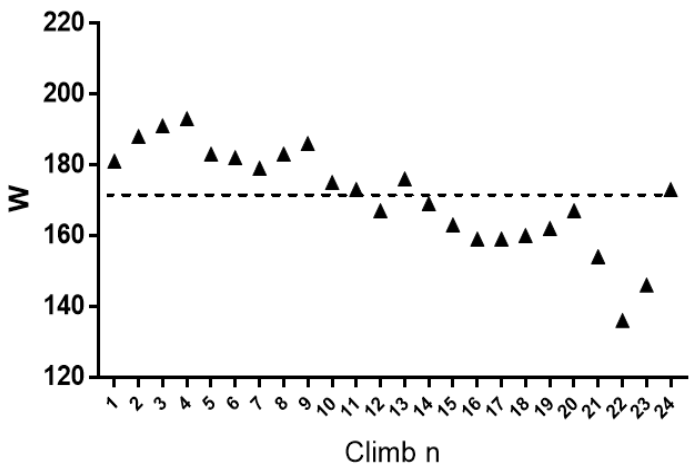

Mean Climbing HR

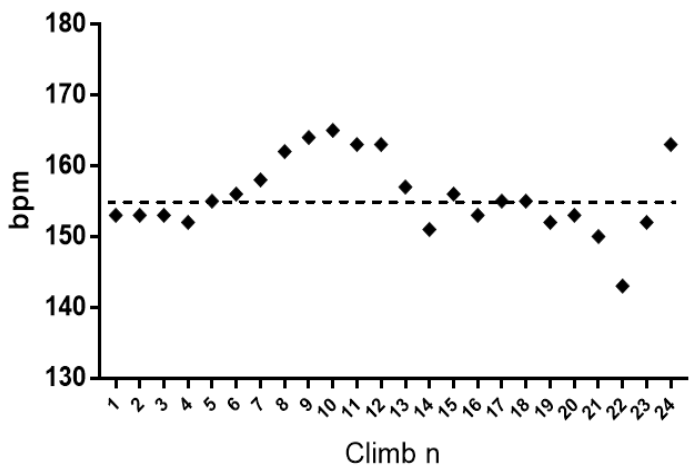

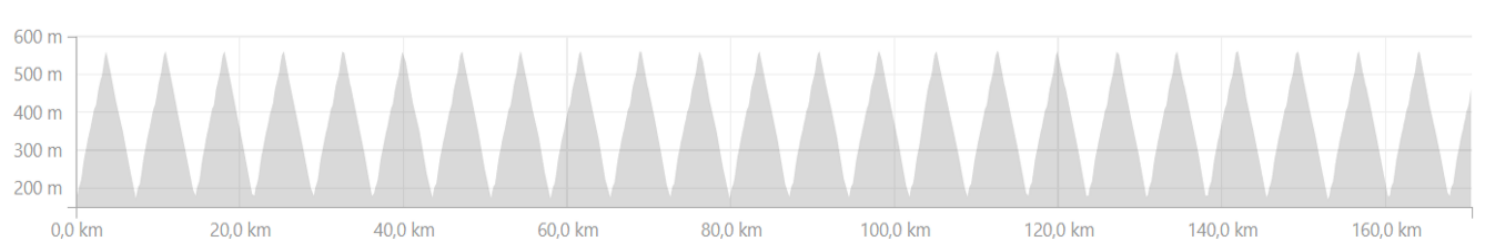

Figure 2. Challenge attempt climbing data. 


\section{Body Composition}

Body weight decreased by $3.4 \mathrm{~kg}$ from T1 to T3 (table 1). Total Body Water (TBW) and in general hydration status (TBW, ECW, ICW) of the athlete was maintained constant during the 10 weeks. Body Cell Mass (BCM) and Phase Angle remained unchanged (figure 3).

Hydration

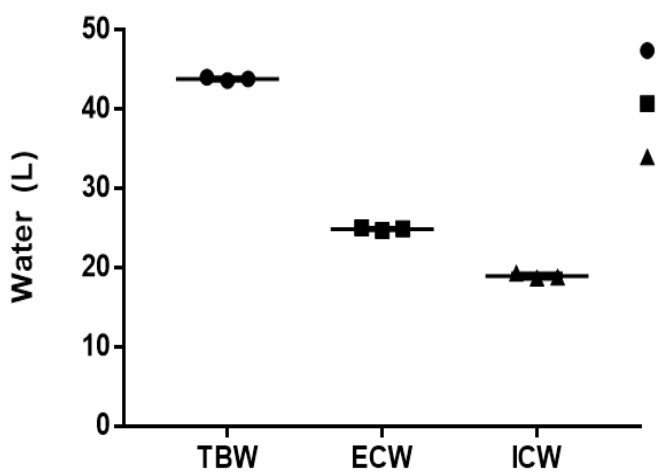

Body Composition

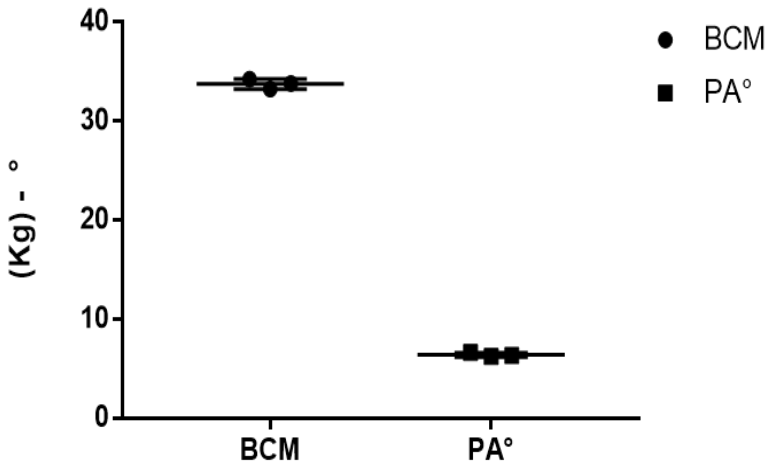

Figure 3. Bioimpedence analysis data (hydration and body composition markers).

Skinfold sum (SUM7) and, parallelly, Body Fat percentage (BF\%) decreased in the first phase $(\mathrm{T} 1 \rightarrow \mathrm{T} 2)$ then stabilized in the second phase of the program $(\mathrm{T} 2 \rightarrow \mathrm{T} 3)$ (table 1, figure 4). Also, body circumferences decreased from T1 to T2 and then remained stable from T2 to T3 (table 1).
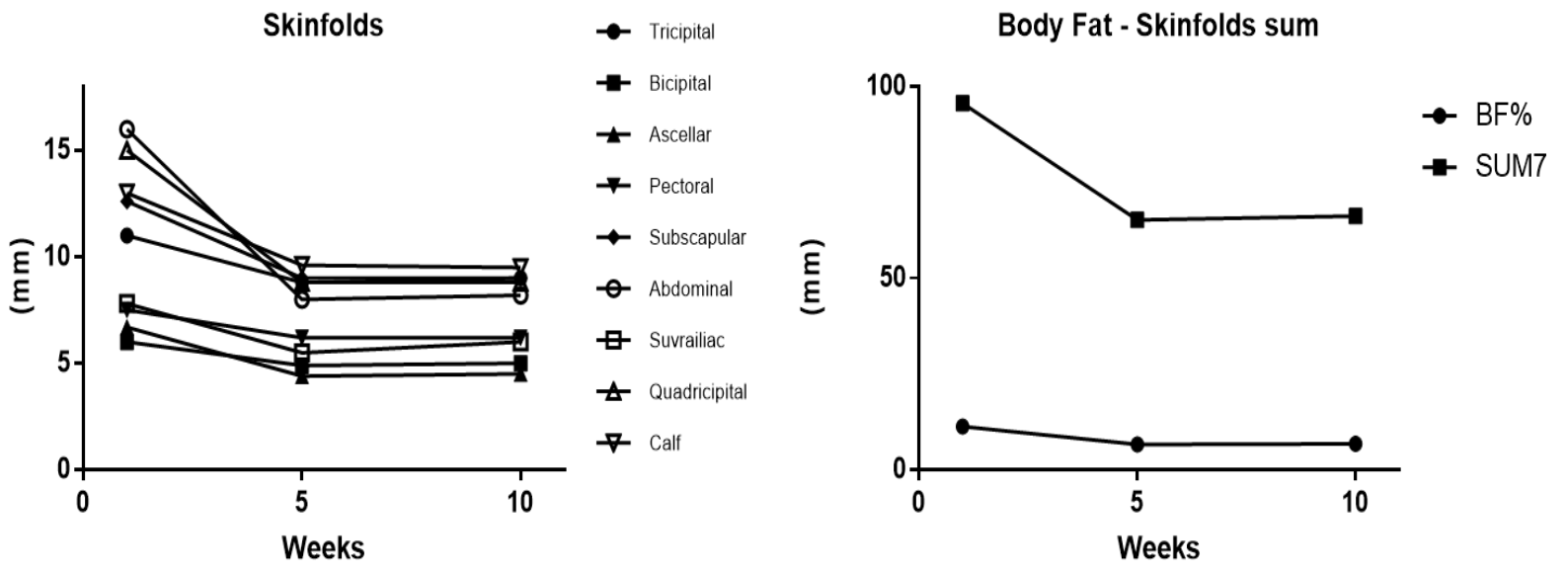

Figure 4. Skinfold thickness and body fat changes during the 10-week program.

Table 1. Body composition changes from T1 to T3.

\begin{tabular}{|c|c|c|c|c|c|}
\hline & \multicolumn{4}{|c|}{ Body Composition } \\
\hline & & $\mathrm{T} 1$ & $\mathrm{~T} 2$ & T3 & $\Delta$ \\
\hline \multicolumn{2}{|c|}{ Body Weight (kg) } & 71.7 & 68.8 & 68.3 & -3.4 \\
\hline \multirow{5}{*}{ 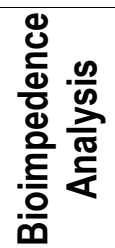 } & $\mathrm{BCM}(\mathrm{kg})$ & 33.2 & 33.8 & 34.2 & +1 \\
\hline & $\mathrm{PA}^{\circ}$ & 6.2 & 6.3 & 6.6 & +0.4 \\
\hline & TBW (L) & 44.00 & 43.8 & 43.6 & -0.4 \\
\hline & ICW (L) & 24.7 & 25.00 & 24.9 & +0.2 \\
\hline & ECW (L) & 19.3 & 18.8 & 18.7 & -0.6 \\
\hline
\end{tabular}

VOLUME 14 | Proc5 | 2019 | S2405 


\begin{tabular}{|c|c|c|c|c|c|c|}
\hline \multirow{9}{*}{ 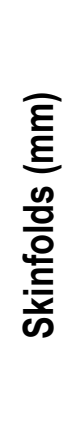 } & & Tricipital & 11.00 & 8.8 & 8.9 & -2.1 \\
\hline & & Bicipital & 6.00 & 4.9 & 5.00 & -1 \\
\hline & & Ascellar & 6.7 & 4.4 & 4.5 & -2.2 \\
\hline & & Pectoral & 7.5 & 6.2 & 6.2 & -1.3 \\
\hline & & Subscapular & 12.6 & 9.00 & 9.00 & -3.6 \\
\hline & & Abdominal & 16.00 & 8.00 & 8.2 & -7.8 \\
\hline & & Suvrailiac & 7.8 & 5.5 & 6.00 & -1.8 \\
\hline & & Quadricipital & 15.00 & 8.8 & 8.8 & -6.2 \\
\hline & & Calf & 13.00 & 9.6 & 9.5 & -3.5 \\
\hline \multirow{14}{*}{ 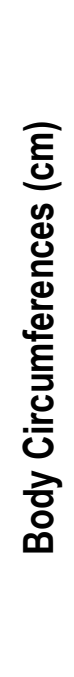 } & & Waist & 75.00 & 73.2 & 72.1 & -2.9 \\
\hline & \multicolumn{2}{|r|}{ Chest } & 91.00 & 89.3 & 89.00 & -2 \\
\hline & \multirow{2}{*}{$\frac{0}{0}$} & Relaxed & 29.00 & 27.8 & 28.00 & -1 \\
\hline & & Contracted & 31.5 & 29.2 & 29.4 & -2.1 \\
\hline & \multirow{2}{*}{$\begin{array}{l}\text { बे } \\
\frac{0}{9} \\
\end{array}$} & Relaxed & 31.5 & 29.2 & 29.4 & -0.9 \\
\hline & & Contracted & 28.00 & 27.00 & 27.1 & -1.3 \\
\hline & \multirow{3}{*}{ 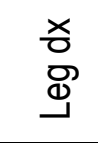 } & Proximal & 53.4 & 51.2 & 51.00 & -2.4 \\
\hline & & Mid & 53.00 & 51.5 & 51.2 & -1.8 \\
\hline & & Distal & 44.3 & 43.2 & 43.00 & -1.3 \\
\hline & \multirow{3}{*}{ 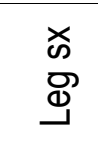 } & Proximal & 53.4 & 51.00 & 51.00 & -2.4 \\
\hline & & Mid & 53.00 & 50.8 & 50.7 & -2.3 \\
\hline & & Distal & 44.2 & 43.2 & 43.1 & -1.1 \\
\hline & & Calf $d x$ & 37.00 & 36.00 & 36.00 & -1 \\
\hline & & Calf sx & 37.00 & 36.00 & 36.00 & -1 \\
\hline
\end{tabular}

\section{Performance}

Power output at $4 \pm 0.3 \mathrm{mmol}$ during the MLSS test increased from T1 to T3 $(+18.0 \mathrm{~W})$ (table 2, figure 5). FTP increased from T1 to T3 (+22.0 W) and, also Conconi's test threshold power (+31.0 W) (table 2, figure $5)$. Power (W) globally increased progressively during the entire program.

MLSS

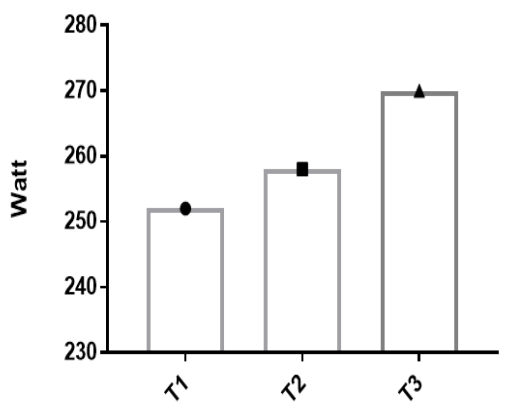

FTP TEST

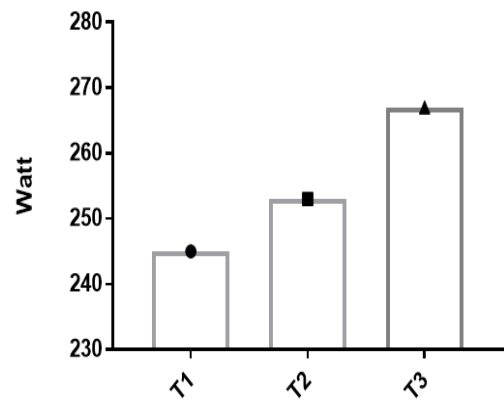

Conconi Test

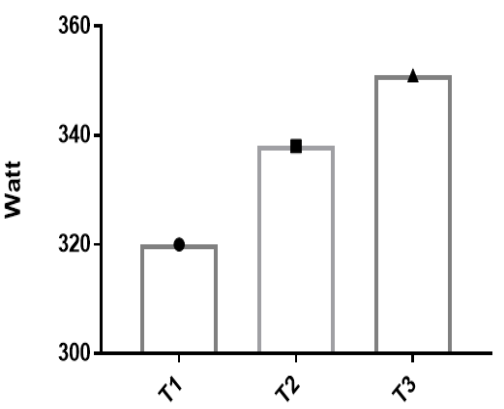

Figure 5. Performance test results at T1 (week 1), T2 (week 5) and T3 (week 10). 
Table 2. Physical condition test results from $\mathrm{T} 1$ to $\mathrm{T} 3$.

\begin{tabular}{|c|c|c|c|c|c|}
\hline \multicolumn{2}{|c|}{} & \multicolumn{4}{|c|}{ Performance Tests } \\
\cline { 3 - 6 } & TLC (mmol/L) & T1 & T2 & T3 & $\Delta$ \\
\hline \multirow{3}{*}{ MLSS } & Power (W) & 252.0 & 4.3 & 4.2 & +0.1 \\
\cline { 2 - 5 } & HR (bpm) & 162.0 & 258.0 & 270.0 & +18.0 \\
\cline { 2 - 5 } & Power (W) & 245.0 & 253.0 & 267.0 & +2.0 \\
\hline \multirow{2}{*}{ FTP } & HR (bpm) & 160.0 & 163.0 & 162.0 & +2.0 \\
\hline \multirow{2}{*}{ Conconi Test } & HR (bpm) & 191.0 & 189.0 & 187.0 & -4.0 \\
\cline { 2 - 6 } & Workload (W) & 320.0 & 338.0 & 351.0 & +31.0 \\
\hline
\end{tabular}

\section{DISCUSSION}

Preparation of an ultra-endurance challenge requires strategically and meticulously planned nutrition and training programs. Our data demonstrates how by periodizing nutrition in relation to training (Jeukendrup, 2017) it is possible to achieve body composition adaptations even in a short period of time. Parallelly how by periodizing training (Allen et al., 2019) in relation to nutrition it is also possible to maximize adaptations in a short period of time.

Considering our aim, the main findings of the present study are related to the achievements in terms of body composition and training adaptations over a relatively short period of time.

In the first phase, in which a caloric deficit was set, and the main focus was on nutrient functional utilization adaptation and on aerobic capacity improvement, it was possible to achieve functional metabolic and body composition adaptations (reduction of $\mathrm{BF} \%$, maintenance of $\mathrm{BCM}$ and $\mathrm{TBW}$ ). Once the objectives related to body composition had been achieved the main focus was on performance optimization and on globally improving physical condition. Functional power but also aerobic capacity increased progressively from $\mathrm{T} 1$ to T3.

Monitoring by using body composition analysis techniques (Bertuccioli et al., 2019; Heydenreich et al., 2017) and performance analysis tests (Löllgen and Leyk, 2018) is fundamental to properly establish and to collect feed-back on nutrition, supplementation and training. Monitoring the athlete's progress and adjusting variables day by day, it is possible to prepare an ultra-endurance event, for an experienced athlete, even in a relatively short period of time.

\section{CONCLUSIONS}

Ten weeks of strategically planned nutrition and training may be sufficient to prepare an élite athlete or a well-trained individual to attempt an ultra-endurance challenge like the Everesting Challenge.

\section{ACKNOWLEDGMENTS}

We would like to thank M.B. who participated in the study. No sources of funding were used in the preparation of this manuscript. 


\section{REFERENCES}

Allen, H., Coggan, A. R., \& McGregor, S. (2019). Training and racing with a power meter. VeloPress.

Baar, K. (2014). Nutrition and the adaptation to endurance training. Sports Med, 44(1), 5-12.

Beneke, R. (2003). Maximal lactate steady state concentration (MLSS): experimental and modelling approaches. Eur J Appl Physiol, 88(4-5), 361-369. https://doi.org/10.1007/s00421-002-0713-2

Beneke, R., Leithäuser, R. M., \& Ochentel, O. (2011). Blood lactate diagnostics in exercise testing and training. Int J Sports Physiol Perform, 6(1), 8-24. https://doi.org/10.1123/ijspp.6.1.8

Bertuccioli, A., Vici, G., Ceci, R., Cesanelli, L., Belli, L., \& Polzonetti, V. (2019). A comparison among infield fat mass evaluation techniques: a practical perspective. Nutrafoods, 1 (26-33). https://doi.org/10.17470/NF-019-0004

Billat, V. L., Sirvent, P., Py, G., Koralsztein, J. P., \& Mercier, J. (2003). The concept of maximal lactate steady state. Sports Med, 33(6), 407-426. https://doi.org/10.2165/00007256-200333060-00003

Burke, L. M., Ross, M. L., Garvican-Lewis, L. A., Welvaert, M., Heikura, I. A., Forbes, S. G., ... \& Hawley, J. A. (2017). Low carbohydrate, high fat diet impairs exercise economy and negates the performance benefit from intensified training in elite race walkers. J Appl Physiol, 595(9), 2785-2807. https://doi.org/10.1113/ip273230

Centers for Disease Control and Prevention. (2007). National health and nutrition examination survey (nhanes): Anthropometry procedures manual. National Center for Health Statistics, editor. Atlanta, GA: Centers for Disease Control. https://doi.org/10.3886/icpsr25505

Compher, C., Frankenfield, D., Keim, N., Roth-Yousey, L., \& Evidence Analysis Working Group. (2006). Best practice methods to apply to measurement of resting metabolic rate in adults: a systematic review. J Am Diet Assoc, 106(6), 881-903. https://doi.org/10.1016/j.jada.2006.02.009

Conconi, F., Grazzi, G., Casoni, I., Guglielmini, C., Borsetto, C., Ballarin, E., ... \& Manfredini, F. (1996). The Conconi test: methodology after 12 years of application. Int J Sports Med, 17(07), 509-519. https://doi.org/10.1055/s-2007-972887

Costa, R. J., Hoffman, M. D., \& Stellingwerff, T. (2019). Considerations for ultra-endurance activities: Part 1-nutrition. Res Sports Med, 27(2), 166-181. https://doi.org/10.1080/15438627.2018.1502188

Heydenreich, J., Kayser, B., Schutz, Y., \& Melzer, K. (2017). Total energy expenditure, energy intake, and body composition in endurance athletes across the training season: a systematic review. Sports Med-open, 3(1), 8. https://doi.org/10.1186/s40798-017-0076-1

Hoffman, M. D., Stellingwerff, T., \& Costa, R. J. (2019). Considerations for ultra-endurance activities: Part 2-hydration. Res Sports Med, 27(2), 182-194. https://doi.org/10.1080/15438627.2018.1502189

Hofmann, P., \& Tschakert, G. (2017). Intensity-and duration-based options to regulate endurance training. Front Physiol, 8, 337. https://doi.org/10.3389/fphys.2017.00337

Hoogeveen, A. R., Hoogsteen, J., \& Schep, G. (1997). The maximal lactate steady state in elite endurance athletes. J Physiol Sci, 47(5), 481-485. https://doi.org/10.2170/ijphysiol.47.481

Impey, S. G., Hearris, M. A., Hammond, K. M., Bartlett, J. D., Louis, J., Close, G. L., \& Morton, J. P. (2018). Fuel for the work required: a theoretical framework for carbohydrate periodization and the glycogen threshold hypothesis. Sports Med, 48(5), 1031-1048. https://doi.org/10.1007/s40279-018$\underline{0867-7}$

Jackson, A. S., \& Pollock, M. L. (1978). Generalized equations for predicting body density of men. Br J Nutr, 40(3), 497-504. https://doi.org/10.1079/bjn19780152

Jeppesen, J., \& Kiens, B. (2012). Regulation and limitations to fatty acid oxidation during exercise. J. Physiol., 590(5), 1059-1068. https://doi.org/10.1113/jphysiol.2011.225011

Jeukendrup, A. E. (2017). Periodized nutrition for athletes. Sports Medicine, 47(1), 51-63. 
Joyner, M. J., \& Coyle, E. F. (2008). Endurance exercise performance: the physiology of champions. J. Physiol., 586(1), 35-44.

Kerksick, C. M., Wilborn, C. D., Roberts, M. D., Smith-Ryan, A., Kleiner, S. M., Jäger, R., ... \& Greenwood, M. (2018). ISSN exercise \& sports nutrition review update: research \& recommendations. J Int Soc Sports Nutr, 15(1), 38. https://doi.org/10.1186/s12970-018-0242-y

Knechtle, B. (2014). Relationship of anthropometric and training characteristics with race performance in endurance and ultra-endurance athletes. Asian J Sports Med, 5(2), 73.

Knechtle, B., \& Nikolaidis, P. T. (2018). Physiology and pathophysiology in ultra-marathon running. Front Physiol, 9, 634. https://doi.org/10.3389/fphys.2018.00634

Löllgen, H., \& Leyk, D. (2018). Exercise testing in sports medicine. Dtsch Arztebl Int, 115(24), 409.

Mazić, S., Lazović, B., Đelić, M., Suzić-Lazić, J., Aćimović, T., \& Brkić, P. (2014). Body composition assessment in athletes: a systematic review. Med. Pregl., 67(7-8), 255-260. https://doi.org/10.2298/mpns1408255m

Nikolaidis, P. T., Knechtle, C., Ramirez-Campillo, R., Vancini, R. L., Rosemann, T., \& Knechtle, B. (2019). Training and Body Composition during Preparation for a 48-Hour Ultra-Marathon Race: A Case Study of a Master Athlete. Int. J. Environ. Res. Public Health, 16(6), 903. https://doi.org/10.3390/ijerph16060903

Nikolaidis, P., Veniamakis, E., Rosemann, T., \& Knechtle, B. (2018). Nutrition in ultra-endurance: State of the art. Nutrients, 10(12), 1995. https://doi.org/10.3390/nu10121995

Perez, I. M., Perez, D. M., Gonzalez, C. C., \& Esteve-Lanao, J. (2012). Prediction of race pace in long distance running from blood lactate concentration around race pace. J Hum Sport Exerc, 7(4), 763769. https://doi.org/10.4100/ihse.2012.74.04

Peters, E. M. (2003). Nutritional aspects in ultra-endurance exercise. Curr Opin Clin Nutr Metab Care, 6(4), 427-434.

Piccoli, A., Rossi, B., Pillon, L., \& Bucciante, G. (1994). A new method for monitoring body fluid variation by bioimpedance analysis: the RXc graph. Kidney Int, 46(2), 534-539. https://doi.org/10.1038/ki.1994.305

Rauch, H. L., Hawley, J. A., Noakes, T. D., \& Dennis, S. C. (1998). Fuel metabolism during ultraendurance exercise. Pflugers Arch., 436(2), 211-219.

Scheer, V. (2019). Participation trends of ultra endurance events. Sports Med Arthrosc, 27(1), 3-7.

Volek, J. S., Noakes, T., \& Phinney, S. D. (2015). Rethinking fat as a fuel for endurance exercise. Eur J Sport Sci., 15(1), 13-20. https://doi.org/10.1080/17461391.2014.959564

Zaryski, C., \& Smith, D. J. (2005). Training principles and issues for ultra-endurance athletes. Urr Sport Med Rep., 4(3), 165-170.

\section{(@) $\odot \Theta \Theta$}

This work is licensed under a Attribution-NonCommercial-NoDerivatives 4.0 International (CC BY-NC-ND 4.0). 